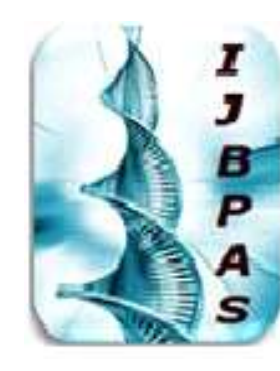

International Journal of Biology, Pharmacy and Allied Seiences (IJBPAS)

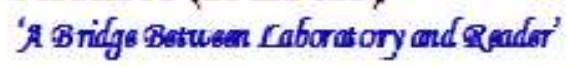

WWW.ijbpas.com

\title{
METHOD DEVELOPMENT AND VALIDATION OF HEAVY METALS IN CARDORIUM PLUS BY USING ICP-OES
}

\section{SNIGDHA DAMIREDDY* AND G. SRIDHAR BABU}

*Corresponding Author: Snigdha Damireddy: E Mail: damireddy.snigdha@gmail.com Received $19^{\text {th }}$ May 2021; Revised $4^{\text {th }}$ June 2021; Accepted $15^{\text {th }}$ July 2021; Available online $25^{\text {th }}$ Sept. 2021 https://doi.org/10.31032/IJBPAS/2021/10.9.1027

\begin{abstract}
An accurate, precise, reproducible method was developed and validated by using Inductively Coupled Plasma Optical Emission Spectroscopy (ICP-OES) for the estimation of arsenic, lead, cadmium and mercury in Cardorium Plus Syrup. The method is selective and is capable to quantitate the respective elements in the presence of other trace elements. The method has been validated using RF power of $1300 \mathrm{~W}$, plasma flow of $13 \mathrm{~L} / \mathrm{min}$, auxiliary gas flow at $0.2 \mathrm{~L} / \mathrm{min}$, nebulizer flow of $0.7 \mathrm{~L} / \mathrm{min}$ with a pump rate of $1 \mathrm{~mL} / \mathrm{min}$ and plasma view is axial mode for all the elements. The wavelength was monitored for Arsenic, Lead, Cadmium and Mercury is at $193.6 \mathrm{~nm}, 220.3 \mathrm{~nm}, 228.8 \mathrm{~nm}$ and $253.6 \mathrm{~nm}$ respectively. The baseline at above stated wavelengths was good and possible inferences were not observed compared to other emission lines of elements. The method has been validated in terms of specificity, precision, linearity, accuracy, limit of quantification. The validated method can be used to estimate elements in other drug substances. The validated method can be used to estimate heavy metals using ICP-OES.
\end{abstract}

Keywords: ICP-OES, Cardorium Plus, ICH, Plasma Flow, Quantification, Validation

\section{INTRODUCTION}

Cardorium plus is an effective herbal remedy for improving the blood circulation. It enhances the blood flow by clearing the blocks and strengthening the blood vessels of the heart. Cardorium plus is available as syrup, which is hygienically formulated using premium grade natural ingredients. It improves fat metabolism, excretion and lipid 
ratios etc. further prevents platelet agglutination, improves the strength of blood vessels. This compound may contain some traces of heavy metals, accidentally added during manufacturing process. These traces are toxic in nature beyond their limit and may lead to unwanted effects. Hence it's necessary to be tested by any analytical techniques like titrations, chromatography, capillary electrophoresis and inductively coupled plasma - optical emission spectroscopy (ICP-OES).

ICP is a versatile tool for detection and quantification of elements in accurate manner. The ICP technique is based on atomic spectrometry. Most specifically, the ICP - OES is emission spectrometric technique that exploits the fact that excited atoms emit energy at a given wavelength as the electrons return to their ground state.

During analysis the sample is decomposed by intense heat into a cloud of hot gases containing free atoms and ions of the elementof interest. The high temperatures cause significant amounts of collisional excitation and ionization of the sample atoms. Once the atoms or ions are in their excited state, they can decay to lower states through thermal or radioactive (emission) energy transitions. A given element emits energy at specificwavelengths peculiar to its chemical character. The intensity of the energy emitted at that wavelength is proportional to the amount of that element in the analyzed sample.

ICP - OES has additional advantages over the other techniques in terms of detection limits as well as speed of analysis. In ICP OES sample experiences temperatures estimated to be in the vicinity of $10,000 \mathrm{~K}$. These results in atomization and excitation of even most refractory elements with high efficiency so that detection limits for these elements with ICP - OES can be well over and order of magnitude better than the corresponding values of other techniques. A new method was developed and validated according to ICH (Q2A 1995) guidelines.

\section{EXPERIMENTAL}

\subsection{Chemicals}

Table 1: Reagents and Chemicals
\begin{tabular}{|c|c|c|}
\hline S. & Chemicals/Reagents/ & Gra \\
N & Standards & de \\
o. & & \\
\hline 1 & Nitric acid (20\% v/v) & \\
\hline 2 & Water & Mill \\
& & i-Q \\
\hline 3 & Cardorium Plus & NA \\
\hline 4 & Arsenic, Lead, & \\
& Cadmium, Mercury & \\
\hline
\end{tabular}

\subsection{Equipment}

Perkin Elmer Inductively coupled plasma system equipped with optical emission spectrophotometry of model Optima 8000.

2.3 Diluent Preparation (20\% V/V Nitric Acid): 
Transfer $200 \mathrm{~mL}$ of Conc. Nitric Acid into a $1000 \mathrm{~mL}$ Volumetric Flask andmake up to volume with milli $Q$ water.

\subsection{Standards Preparation:}

Standard Stock Solution Preparation 1 (10 PPM of Cadmium)

Take $0.1 \mathrm{~mL}$ of $1000 \mathrm{PPM}$ of cadmium standard solution into a $10 \mathrm{~mL}$ Volumetric Flask and make up to volume with diluent.

\section{Standard Stock Solution Preparation 2}

Transfer $0.03 \mathrm{~mL}$ of above standard stock solution 1 into a $10 \mathrm{~mL}$ Volumetric Flask and add $0.03 \mathrm{~mL}$ of 1000 PPM of Arsenic Standard Solution, $0.1 \mathrm{~mL}$ of 1000PPM lead standard solution, $0.01 \mathrm{~mL}$ of $1000 \mathrm{PPM}$ mercury standard solution and make up to volume with diluent respectively.

\subsection{Sample Preparation}

Taken $2 \mathrm{gm}$ of cardorium plus syrup sample in to a $10 \mathrm{~mL}$ volumetric flask add $2 \mathrm{~mL}$ of Conc. Nitric acid and allow to digest on a water bath at $90{ }^{0} \mathrm{C}$ for about $20 \mathrm{~min}$ cool the sample and make up with Milli Q water. Filter the sample and use for aspirations.

\subsection{Method Development}

The main objective of the study is to develop a suitable ICP-OES method to quantify arsenic, lead, cadmium and mercury present in cardorium plus.

During method development arsenic, lead, cadmium and mercury standards were prepared and monitored at different possible emission lines with applied target RF power of $1300 \mathrm{~W}$. The responses for Arsenic, Lead, Cadmium and Mercury are very prominent at $193.6 \mathrm{~nm}, 220.3 \mathrm{~nm}, 228.8 \mathrm{~nm}$ and $253.6 \mathrm{~nm}$ respectively. The baseline at above stated wavelengths was good and possible inferences were not observed compared to other emission lines of elements.

\subsection{ICP-OES Conditions}

The RF power used was $1300 \mathrm{~W}$, plasma flow was $13 \mathrm{~L} / \mathrm{min}$, auxiliary gas flow was kept at $0.2 \mathrm{~L} / \mathrm{min}$, nebulizer flow was kept at $0.7 \mathrm{~L} / \mathrm{min}$, and pump rate was kept at 1 $\mathrm{mL} / \mathrm{min}$. Plasma view was in axial view. Three replicates were performed.

\subsection{Method Validation}

\subsubsection{Linearity}

Linearity is the first analytical method validation parameter is done to elicit test results that are directly proportional to the concentration of analyte in samples within a given range. Linearity was evaluated by preparing a linear series of standard solutions of Arsenic, Lead, Cadmium and Mercury in the concentrations range of $50 \%, 100 \%$ and $150 \%$ level specifications. For sample prepararions, transfer $1 \mathrm{~mL}, 2 \mathrm{~mL}, 3 \mathrm{~mL}$ from standard stock solution preparation 2 into 10 $\mathrm{mL}$ volumetric flask individually and dilute up to mark by using diluent. 


\begin{tabular}{|c|c|c|c|}
\hline & $\begin{array}{c}\mathbf{5 0} \% \\
\text { Preparation }\end{array}$ & $\begin{array}{c}\mathbf{1 0 0 \%} \\
\text { Preparation }\end{array}$ & $\begin{array}{c}150 \% \\
\text { Preparation }\end{array}$ \\
\hline Arsenic & $\mathbf{0 . 3}$ & $\mathbf{0 . 6}$ & $\mathbf{0 . 9}$ \\
\hline Lead & 1 & $\mathbf{2}$ & $\mathbf{3}$ \\
\hline Cadmium & $\mathbf{0 . 0 3}$ & $\mathbf{0 . 0 6}$ & $\mathbf{0 . 0 9}$ \\
\hline Mercury & $\mathbf{0 . 1}$ & $\mathbf{0 . 2}$ & $\mathbf{0 . 3}$ \\
\hline
\end{tabular}

\begin{tabular}{|c|c|c|c|c|}
\hline & Arsenic & Lead & Cadmium & Mercury \\
\hline Standard-1 & $\mathbf{5 8 7 . 5}$ & $\mathbf{1 9 3 6 . 0}$ & $\mathbf{4 1 4 4 7 . 4}$ & $\mathbf{3 8 3 8 . 6}$ \\
\hline Standard-2 & $\mathbf{1 0 3 7 . 7}$ & $\mathbf{3 7 2 2 . 9}$ & $\mathbf{8 1 2 5 4}$ & $\mathbf{6 8 5 8 . 6}$ \\
\hline Standard-3 & $\mathbf{1 6 3 6 . 6}$ & $\mathbf{5 5 9 9 . 6}$ & $\mathbf{1 1 7 3 2 2 . 6}$ & $\mathbf{9 4 1 7 . 7}$ \\
\hline
\end{tabular}
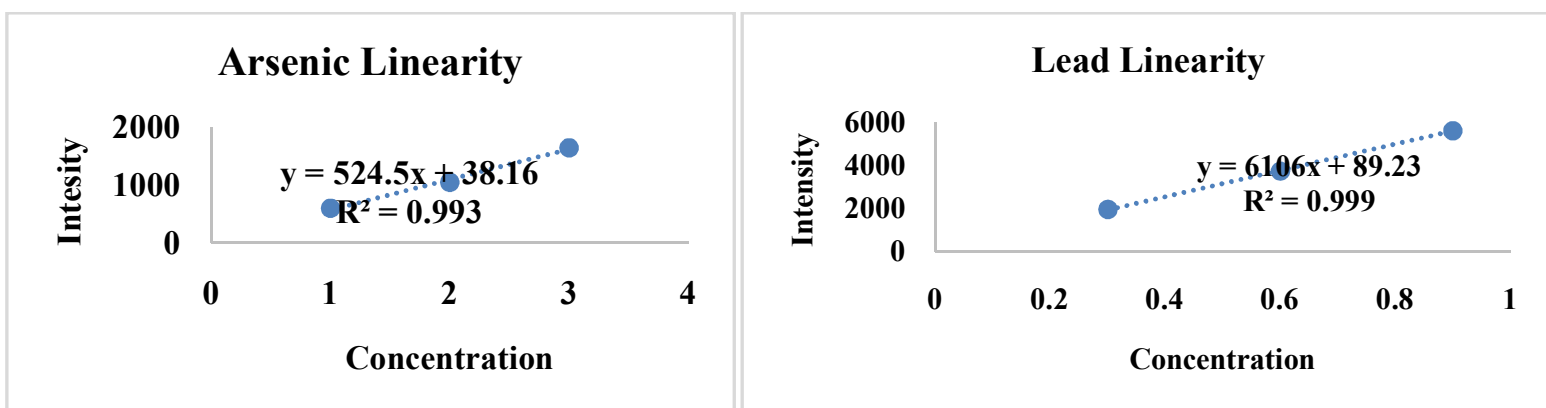

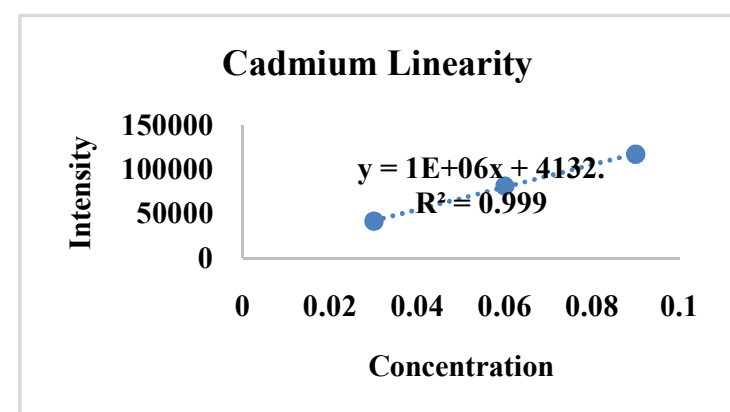

The correlation coefficient for Arsenic, Lead, Cadmium and Mercury were found to be $0.993,0.999,0.999$ and 0.997 respectively which indicates good linearity.

\subsubsection{Specificity:}

Specificity is the ability to assess unequivocally the analyte in the presence of components that may be expected to be present, such as impurities, degradation products and matrix components.

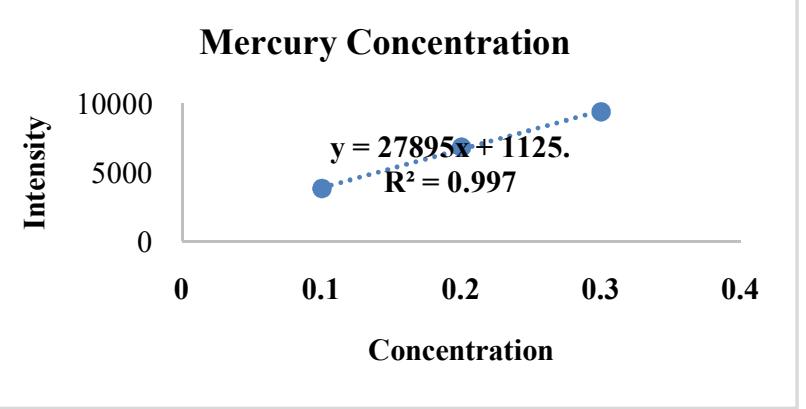

The test samples in triplicate and test sample spiked with multi elements including arsenic, lead, cadmium and mercury (spiked sample) in triplicate were aspirated as per test method and individual metal contents were determined. $100 \%$ spike sample is prepared and diluted with nitric acid and appropriate $\%$ recoveries were found. 


\begin{tabular}{|c|c|c|c|}
\hline & Spike Conc (PPM) & Amount Recovered & \% Recovery \\
\hline Arsenic & $\mathbf{0 . 6}$ & $\mathbf{0 . 5 7}$ & 95 \\
\hline Lead & $\mathbf{2}$ & $\mathbf{1 . 8 9}$ & $\mathbf{9 4 . 5}$ \\
\hline Cadmium & $\mathbf{0 . 0 6}$ & $\mathbf{0 . 0 5 2}$ & $\mathbf{8 6 . 7}$ \\
\hline Mercury & $\mathbf{0 . 2}$ & $\mathbf{0 . 2 1}$ & $\mathbf{1 0 5}$ \\
\hline
\end{tabular}

Sample:

\begin{tabular}{|c|c|}
\hline Arsenic & Not Detected \\
\hline Lead & Not Detected \\
\hline Cadmium & Not Detected \\
\hline Mercury & Not Detected \\
\hline
\end{tabular}

\subsubsection{Precision}

Precision of analytical method is the degree of agreement among the individual test results when the procedure is applied repeatedly to multiple samplings of a homogenous sample. This can be expressed by Standard Deviation [SD] or Percent Relative Standard Deviation [\%RSD].

Precision was checked for both system and method. Method precision was checked by analyzing Cardorium plus sample drug substance prepared as per the test method.
The system precision was checked by analyzing six replicates each of standard solutions of Arsenic, Lead, Cadmium and Mercury prepared at concentration of $100 \%$ standard and spike solution. The concentration of each element for each replication was calculated by using the calibration standards. The \%RSD was found to be within the specification.

\section{System Precision:}

100 \% - 6 Replicates Standard Solution

\begin{tabular}{|c|c|c|c|c|c|c|c|c|c|c|}
\hline & $\begin{array}{c}\text { Actual } \\
\text { Conc }\end{array}$ & $\begin{array}{c}\text { Preparat } \\
\text { ion 1 }\end{array}$ & 2 & 3 & 4 & 5 & 6 & Mean & SD & $\%$ RSD \\
\hline Arsenic & $\mathbf{0 . 6}$ & $\mathbf{0 . 5 9}$ & $\mathbf{0 . 6 8}$ & $\mathbf{0 . 5 8}$ & $\mathbf{0 . 6 1}$ & $\mathbf{0 . 5 9}$ & $\mathbf{0 . 6 2}$ & $\mathbf{0 . 6 1}$ & $\mathbf{0 . 0 3 7}$ & $\mathbf{5 . 9 8}$ \\
\hline Lead & $\mathbf{2}$ & $\mathbf{1 . 9 8}$ & $\mathbf{1 . 9 6}$ & $\mathbf{2 . 0 2}$ & $\mathbf{1 . 9 9}$ & $\mathbf{2 . 0}$ & $\mathbf{2 . 0 1}$ & $\mathbf{1 . 9 9}$ & $\mathbf{0 . 0 2 2}$ & $\mathbf{1 . 0 8}$ \\
\hline Cadmium & $\mathbf{0 . 0 6}$ & $\mathbf{0 . 0 6 1}$ & $\mathbf{0 . 0 5 4}$ & $\mathbf{0 . 0 5 7}$ & $\mathbf{0 . 0 5 8}$ & $\mathbf{0 . 0 5 9}$ & $\mathbf{0 . 0 6 2}$ & $\mathbf{0 . 0 6}$ & $\mathbf{0 . 0 0 3}$ & $\mathbf{4 . 9 2}$ \\
\hline Mercury & $\mathbf{0 . 2}$ & $\mathbf{0 . 1 9 7}$ & $\mathbf{0 . 2 0 4}$ & $\mathbf{0 . 1 9 8}$ & $\mathbf{0 . 2 1 0}$ & $\mathbf{0 . 1 9 9}$ & $\mathbf{0 . 1 9 5}$ & $\mathbf{0 . 2 0}$ & $\mathbf{0 . 0 0 6}$ & $\mathbf{2 . 7 6}$ \\
\hline
\end{tabular}

\section{Method Precision:}

\begin{tabular}{|l|l|}
\hline & $\begin{array}{l}\text { Actual } \\
\text { Conc }\end{array}$ \\
\hline Arsenic & $\mathbf{0 . 6}$ \\
\hline Lead & $\mathbf{2}$ \\
\hline Cadmium & $\mathbf{0 . 0 6}$ \\
\hline Mercury & $\mathbf{0 . 2}$ \\
\hline
\end{tabular}




\subsubsection{Accuracy}

Accuracy is the measure of exactness of an analytical method, or the closeness of agreement between the measured value and the value of an accepted reference value.

Accuracy performed at $50 \%, 100 \%, 150 \%$ levels. Each level three individual spike sample preparations were done. The recovery of the respective elements ranged from 93.3106.7\% [Acceptance criteria: 80.0-120.0\%].

\section{0 \% Spike Sample Preparation:}

\begin{tabular}{|c|c|}
\hline & Actual Conc \\
\hline Arsenic & 0.3 \\
\hline Lead & 1.0 \\
\hline Cadmium & $\mathbf{0 . 0 3}$ \\
\hline Mercury & 0.1 \\
\hline
\end{tabular}

\begin{tabular}{|c|c|c|}
\hline Preparation & $\begin{array}{c}\text { Observed } \\
\text { Concentration }\end{array}$ & \% Recovery \\
\hline \multicolumn{3}{|l|}{ Preparation 1} \\
\hline Arsenic & 0.29 & $96.7 \%$ \\
\hline Lead & 1.04 & $104.0 \%$ \\
\hline Cadmium & 0.027 & $90.0 \%$ \\
\hline Mercury & 0.11 & $110.0 \%$ \\
\hline \multicolumn{3}{|c|}{ Preparation 2} \\
\hline Arsenic & 0.31 & $103.3 \%$ \\
\hline Lead & 0.989 & $98.9 \%$ \\
\hline Cadmium & 0.031 & $103.3 \%$ \\
\hline Mercury & 0.096 & $96.0 \%$ \\
\hline \multicolumn{3}{|c|}{ Preparation 3} \\
\hline Arsenic & 0.294 & $98.0 \%$ \\
\hline Lead & 1.02 & $102.0 \%$ \\
\hline Cadmium & 0.029 & $96.7 \%$ \\
\hline Mercury & 0.104 & $104.0 \%$ \\
\hline
\end{tabular}

100 \% Spike Sample Preparation:

\begin{tabular}{|c|c|c|c|}
\hline & $\begin{array}{l}\text { Actual } \\
\text { Conc }\end{array}$ & & \\
\hline Arsenic & 0.6 & & \\
\hline Lead & 2.0 & & \\
\hline Cadmium & 0.06 & & \\
\hline Mercury & 0.2 & & \\
\hline & aration & Observed Concentration & \% Recovery \\
\hline \multicolumn{4}{|c|}{ Preparation 1} \\
\hline & enic & 0.58 & $96.7 \%$ \\
\hline & ead & 2.07 & $103.5 \%$ \\
\hline & mium & 0.064 & $106.7 \%$ \\
\hline & rcury & 0.192 & $96.0 \%$ \\
\hline \multicolumn{4}{|c|}{ Preparation 2} \\
\hline & senic & 0.61 & $101.7 \%$ \\
\hline & ead & 1.987 & $99.4 \%$ \\
\hline
\end{tabular}

IJBPAS, September, Special Issue, 2021, 10(9) 


\begin{tabular}{|c|c|c|}
\hline Cadmium & $\mathbf{0 . 0 5 7}$ & $\mathbf{9 5 . 0 \%}$ \\
\hline Mercury & $\mathbf{0 . 2 1}$ & $\mathbf{1 0 5 \%}$ \\
\hline \multicolumn{3}{|c|}{ Preparation 3 } \\
\hline Arsenic & $\mathbf{0 . 5 7}$ & $\mathbf{9 5 . 0 \%}$ \\
\hline Lead & $\mathbf{2 . 0 1}$ & $\mathbf{1 0 0 . 5 \%}$ \\
\hline Cadmium & $\mathbf{0 . 0 5 9}$ & $\mathbf{9 8 . 3 \%}$ \\
\hline Mercury & $\mathbf{0 . 1 9 7}$ & $\mathbf{9 8 . 5 \%}$ \\
\hline
\end{tabular}

150 \% Spike Sample Preparation:

\begin{tabular}{|c|c|c|c|}
\hline & $\begin{array}{c}\text { Actual } \\
\text { Conc }\end{array}$ & & \\
\hline Arsenic & 0.9 & & \\
\hline Lead & 3.0 & & \\
\hline Cadmium & 0.09 & & \\
\hline Mercury & 0.3 & & \\
\hline \multicolumn{2}{|c|}{ Preparations } & Observed Concentration & \% Recovery \\
\hline \multicolumn{4}{|c|}{ Preparation 1} \\
\hline & enic & 0.89 & $98.9 \%$ \\
\hline & ead & 3.09 & $102.3 \%$ \\
\hline & mium & 0.084 & $93.3 \%$ \\
\hline & cury & 0.29 & $96.7 \%$ \\
\hline \multicolumn{4}{|c|}{ Preparation 2} \\
\hline & enic & 0.91 & $101.1 \%$ \\
\hline & ead & 2.94 & $98.0 \%$ \\
\hline & mium & 0.092 & $102.2 \%$ \\
\hline & cury & 0.31 & $103.3 \%$ \\
\hline \multicolumn{4}{|c|}{ Preparation 3} \\
\hline & enic & 0.894 & $99.3 \%$ \\
\hline & ead & 3.1 & $103.3 \%$ \\
\hline & mium & 0.087 & $96.7 \%$ \\
\hline & cury & 0.28 & $93.3 \%$ \\
\hline
\end{tabular}

\subsubsection{LOD \& LOQ}

Limit of detection is defined as the lowest concentration of an analyte ina sample that can be detected, though not necessarily quantitated. It is a limit test that specifies whether or not an analyte is above or below a certain value.

\begin{tabular}{|c|c|}
\hline & $\begin{array}{c}\text { LOQ Solution } \\
\text { Conc (PPM) }\end{array}$ \\
\hline Arsenic & 0.12 \\
\hline Lead & 0.4 \\
\hline Cadmium & 0.012 \\
\hline Mercury & 0.04 \\
\hline
\end{tabular}

Limit of quanitification is defined as the lowest concentration of an analyte ina sample that can be determined with acceptable precision and accuracy under the stated operational conditions of the method. LOD is directly proportional to the precision.

Different LOD and LOQ concentrations were prepared and analysed.

\begin{tabular}{|c|c|}
\hline & $\begin{array}{c}\text { LOD Solution } \\
\text { Conc (PPM) }\end{array}$ \\
\hline Arsenic & 0.036 \\
\hline Lead & 0.12 \\
\hline Cadmium & 0.72 \\
\hline Mercury & 0.012 \\
\hline
\end{tabular}




\subsubsection{Ruggedness}

The Ruggedness of a method was defined as degree of reproducibility of results obtained by analysis of the same sample under variety of normal test conditions such as different labs, different analysts, different instruments and different lots of reagents.

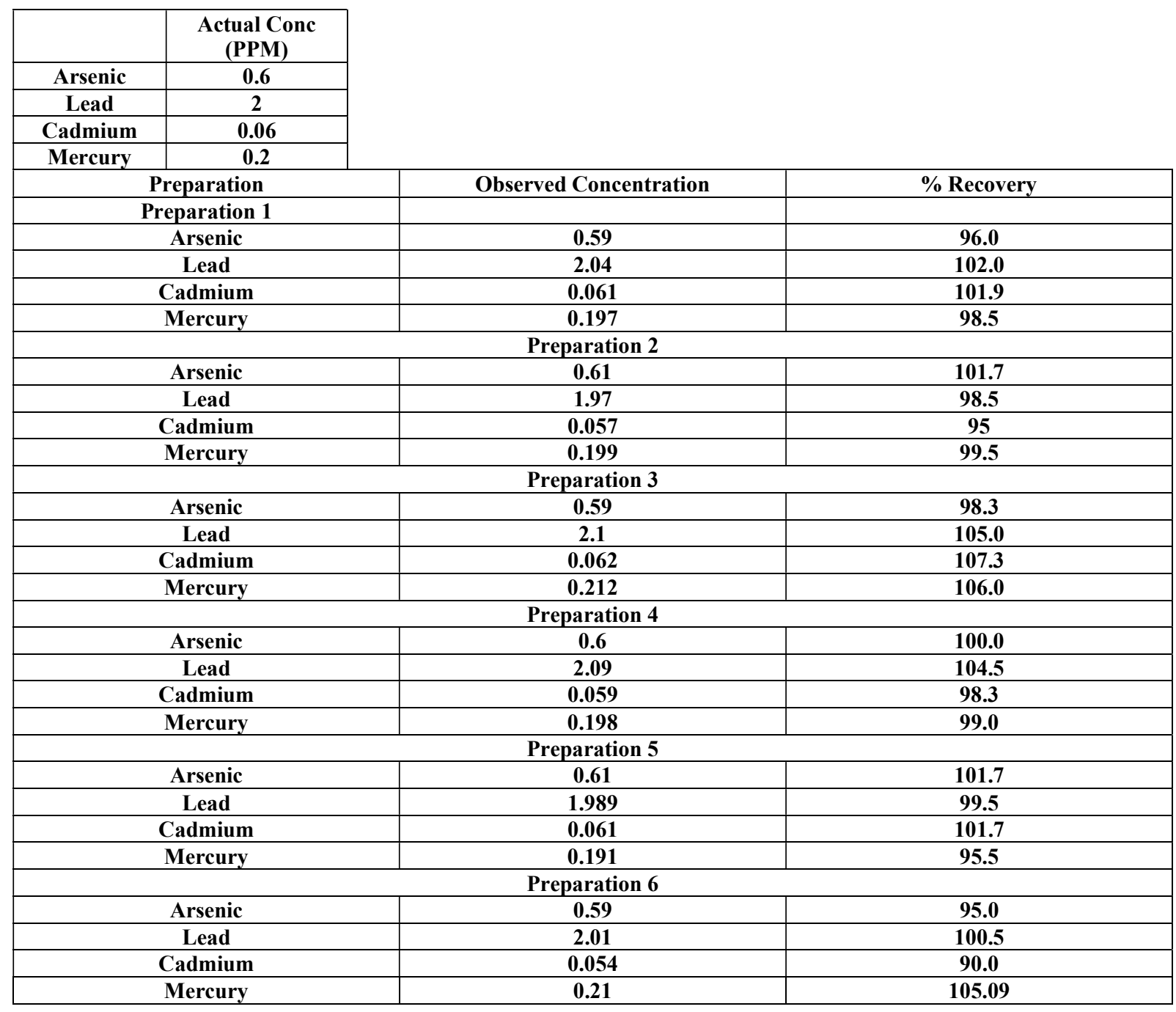

\section{CONCLUSION}

A validated and accurate ICP-OES method has been developed to estimate Arsenic, Lead, Cadmium and Mercury in Cardorium Plus drug substance. The heavy metals in the given sample were below detection level in the given sample. The method is selective and is capable to quantitate the respective elements in the presence of other trace elements. The method has been validated in terms of specificity, precision, linearity, accuracy and limit of quantification. The validated method can be used to estimate elements in other drug substances. 


\section{ACKNOWLEDGEMENTS}

I take this privilege and pleasure to acknowledge the contributions of many individuals who are supportive to my work. I specially thank my guide for moral support and encouragement during the work and to Aurobindo Pharmaceuticals, Hyderabad, for providing necessary facilities to carry out this research work.

\section{REFERENCES}

[1] Perkin Elmer's Guide to inorganic analysis in AA, ICP-OES and ICPMS.

[2] Nobrega A. Joaquim et al; Evaluation of inductively coupled plasma optical emission spectrometers with axially and radially viewed configurations. Elsevier Science B.V., Spectrochimia Acta part B 57(2002).

[3] J. W. Olesik, "Spectrometers," in Inductively Coupled Plasma Emission Spectroscopy, Part 1, Methodology, Instrumentation, and Performance, $\mathrm{P}$. W. J. M. Boumans, Ed., Wiley, New York, NY, USA, 1987.

[4] C. B. Boss and K. J. Fredeen, "Concepts, Instrumentation and Techniques in Inductively Coupled Plasma Optical Emission Spectrometry," $3^{\text {rd }}$ Edition, Perkin Elmer, Waltham, 1997.
[5] P. W. J. M. Boumans, "Inductively Coupled Plasma Emission Spectroscopy-Part 2,” In: P. J. Elving and J. D. Winefordner, Eds., Chemical Analysis, John Wiley \& Sons, New York, Vol. 90, 1987.

[6] M. Thompson and J. N. Walsh, "A Handbook of Inductively Coupled Plasma Spectrometry," Blackie, Glasgow, 1983.

[7] Validation of Analytical procedures: methodology, ICH Harmonised tripartite Guideline, 1996, 1-8, [online] available at www.ich.org.

[8] https://www.ayurvikalp.com/product/ alakanada-herbal-cardorium-plus300ml-ayuvedic-cardiac-tonic. 